\title{
Commentary: Fixing the hole
}

\author{
Donald D. Glower, MD
}

Dershowitz and colleauges ${ }^{1}$ present a case of transcatheter repair of both an apical left ventricular pseudoaneurysm and bioprosthetic mitral structural valve dysfunction. The authors present this case to demonstrate the efficacy of the technique as a potential salvage for high-risk patients with mitral structural valve dysfunction and left ventricular pseudoaneurysm.

As transcatheter approaches to the cardiac valves become increasingly frequent, there will be inevitable cardiac perforations either from the device or, more likely, from the catheters or wires themselves. As in this case, acute perforations will need surgical repair for the foreseeable future. Apical left ventricular pseudoaneurysm can occur after any transapical access to the mitral or aortic valves. The incidence of pseudoaneurysm after surgical repair of the left ventricular apex is $1 \%$. $^{2}$

Once chronic left ventricular pseudoaneurysm occurs after surgical closure, percutaneous closure of left ventricular pseudoaneurysm has been reported. ${ }^{1,3}$ The unique aspect of this report was the ability to successfully repair the late pseudo aneurysm with a transcatheter approach while at the same time performing valve-in-valve mitral replacement. In other situations, left ventricular apical perforation may occur or be recognized after transcatheter valvein-valve mitral replacement. In that case, the transcatheter technique described by Dershowitz and colleagues would still be applicable for repair of any late pseudoaneurysm without needing to address the mitral valve.

This well-documented case does offer an alternative to surgical reoperation on those rare left ventricular

From the Division of Cardiothoracic Surgery, Department of Surgery, Duke University Medical Center, Durham, NC.

Disclosures: The author reported no conflicts of interest.

The Journal policy requires editors and reviewers to disclose conflicts of interest and to decline handling or reviewing manuscripts for which they may have a conflict of interest. The editors and reviewers of this article have no conflicts of interest.

Received for publication Feb 23, 2020; revisions received Feb 23, 2020; accepted for publication Feb 24, 2020; available ahead of print March 4, 2020.

Address for reprints: Donald D. Glower, MD, Duke University Medical Center, Box 3851, Durham, NC 27710 (E-mail: Glowe001@mc.duke.edu).

JTCVS Techniques 2020;3:130

2666-2507

Copyright $@ 2020$ The Authors. Published by Elsevier Inc. on behalf of The American Association for Thoracic Surgery. This is an open access article under the CC BY-NCND license (http://creativecommons.org/licenses/by-nc-nd/4.0/).

https://doi.org/10.1016/j.xjtc.2020.02.022

pseudoaneurysms that might recur. The left ventricular apex has long been a challenge in the surgical experience to obtain both acute and chronic control of perforations or cannulation sites. ${ }^{2}$ When it comes to repairing left ventricular pseudoaneurysm, transcatheter and not open approaches may be preferable means for fixing the hole.

\section{References}

1. Dershowitz L, Wolbinski M, Bapat V, George I, Kodali S. Left ventricular injury: beware the wire. J Thorac Cardiovasc Surg Tech. 2020;3:126-9.

2. Pasic M, Buz S, Dreysse S, Drews T, Unbehaun A, Klein C, et al. Transapical aortic valve implantation in 194 patients: problems, complications, and solutions. Ann Thorac Surg. 2010;90:1463-9.

3. Feldman T, Pearson P, Smart SS. Percutaneous closure of post TAVR LV apical pseudoaneurysm. Catheter Cardiovasc Interv. 2016;88:479-85.

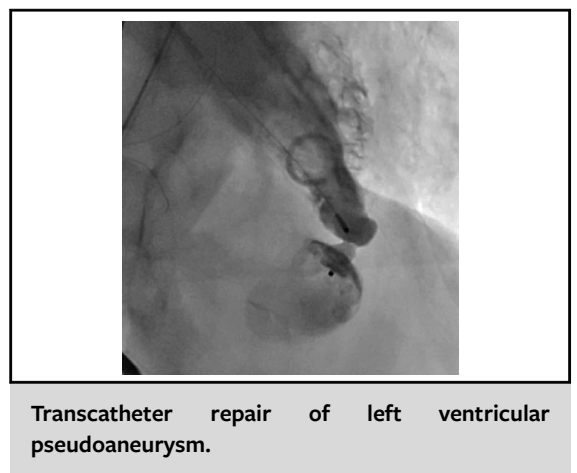

CENTRAL MESSAGE

Concurrent transcatheter repair

of both apical left ventricular

pseudoaneurysm and bio-

prosthetic mitral structural valve

dysfunction is described. 